\title{
Nerve conduction velocity in experimental diabetes in the rat and rabbit
}

\author{
P K THOMAS, J G R JEFFERYS, * A K SHARMA, \\ A N D S B A J A D A $\dagger$ \\ From the Department of Neurological Science, Royal Free Hospital School of Medicine, London
}

SUMMARY Tibial motor nerve conduction velocity was measured in rats, before and two months after the induction of diabetes with streptozotocin. A second group of diabetic animals was also administered $1 \%$ dietary myoinositol supplements. An analysis of variance was performed on these data. Myoinositol supplements had no effect whatsoever. The period of diabetes had a statistically significant and quantitatively marginal effect (a decrease of $2 \cdot 2 \mathrm{~m} \mathrm{~s}^{-1}$ ) on conduction velocity. This is considerably less than in previous reports. The reasons for this are discussed. Tibial motor nerve conduction velocity was also measured in a group of alloxandiabetic rabbits two months after the induction of diabetes and in an age-matched control group. Conduction velocity was again slightly but significantly less in the diabetic animals.

Eliasson ${ }^{1}$ first reported reduced nerve conduction velocity in the sciatic nerves of rats made diabetic with alloxan. In a later study on isolated nerve fibres, ${ }^{2}$ he attributed this to a diminution in the electrical resistance of the myelin. Reduced nerve conduction velocity was found by numerous other authors in alloxan-diabetic rats $^{3-x}$ and subsequently in streptozotocin-diabetic rats. ${ }^{9-11}$ Eliasson ${ }^{1}$ was unable to show any improvement in conduction velocity with insulin treatment but this was later claimed by Preston ${ }^{3}$ and others. ${ }^{6} 1011$ It was therefore suggested by Jakobsen and Lundbaek ${ }^{12}$ that the reduction might be equivalent to the changes found in newly diagnosed diabetes in man that are rapidly corrected by the institution of treatment. ${ }^{1314}$ Mayher et al ${ }^{15}$ reported that the reduced conduction velocity in alloxan-diabetic rats could be improved by hypophysectomy and Greene et $a l^{10}$ claimed that a small dietary myoinositol supplement prevents the reduction in streptozotocin-diabetic rats.

The explanation for the reduced nerve conduction velocity has been a matter of dispute. Preston ${ }^{3}$ and Hildebrand et $a l^{5}$ reported paranodal and segmental demyelination, but this was not con-

*Present address: Sobell Department of Neurophysiology, Institute of Neurology, Queen Square London.

†Present address: Department of Neurology and Clinical Neurophysiology, Fremantle Hospital, Fremantle, Western Australia.

Address for reprint requests: Professor PK Thomas, Royal Free Hospital, Pond Street, London NW3 2QG.

Accepted 26 August 1980 firmed by Sharma and Thomas ${ }^{9}$ or Jakobsen. ${ }^{16}$ Eliasson ${ }^{1}$ and Sharma and Thomas $^{9}$ found no alteration in fibre diameter but Jakobsen and Lundbaek $^{12}$ and Jakobsen ${ }^{11} 17$ later showed that nerve fibre diameter was less in the diabetic animals than in age-matched controls, this affecting axon diameter to a greater extent than myelin thickness. Sharma et al ${ }^{18}$ could not demonstrate any absolute reduction in the external diameter of myelinated nerve fibres, that is with measurements taken to the outer aspects of the myelin sheaths, in serial observations on streptozotocin-diabetic rats before and after the induction of diabetes. Rats are known to continue growing until approximately 9 months of age, this affecting both nerve fibre diameter and conduction velocity. 91920 The difference in conduction velocity between the diabetic and control animals could therefore be due to an impairment in the maturation of nerve fibre diameter produced by the diabetes. Streptozotocin diabetes retards both growth in nerve fibre diameter and skeletal growth in rats. ${ }^{21}$

Most observations on changes in nerve conduction velocity in experimental diabetes have been performed on rats during the period of rapid growth. This undoubtedly complicates interpretation of the results. In this study we have therefore made serial observations on streptozotocin-diabetic rats using mature animals to obviate this difficulty. We have also made observations on alloxandiabetic rabbits, which have not previously been 
studied electrophysiologically. In addition, we have made a further assessment of the possible influence of low dose dietary myoinositol supplements on nerve conduction velocity.

\section{Methods}

Induction of diabetes Diabetes was induced in male Wistar rats aged approximately 9 months (weight 490 $660 \mathrm{~g}$ ) by the intraperitoneal injection of streptozotocin at a dosage of $55 \mathrm{mg} \mathrm{kg}^{-1}$ body weight. Although younger animals tolerate higher amounts than this, for mature animals, dosages of $65 \mathrm{mg} \mathrm{kg}^{-1}$ and above lead to a high mortality in the acute stage after administration. Animals were accepted as diabetic when blood sugar concentrations exceeded $19.4 \mathrm{mmol} \mathrm{l}^{-1}$ $\left(350 \mathrm{mg} \mathrm{dl}^{-1}\right)$ as recommended by Greene et al. ${ }^{10}$ The rats were maintained for two months in plastic metabolic cages on $41 \mathrm{~B}$ Oxoid diet (Lillico) with water ad libitum. A two month survival period was chosen in an attempt to avoid any acute changes that might be related to alloxan or streptozotocin toxicity. Eliasson ${ }^{1}$ reported that the degree of reduction in conduction velocity is greater during the early period after induction of diabetes in rats with alloxan; this was attributed to a direct toxic effect of alloxan. The rats given supplementary myoinositol were administered $1 \%$ myoinositol (Sigma) by weight in a diet according to the regime adopted by Greene et al. ${ }^{10}$ The untreated 41B diet contained $0.023 \%$ myoinositol. ${ }^{22}$

For the studies on rabbits, male New Zealand white rabbits were received at about two months of age (approximately $2 \mathrm{~kg}$ in weight) and maintained in individual metal cages with water ad libitum and RGP Pellet No 478 (Grain Harvesters Ltd) diet. Within a few days of arrival, diabetes was induced in randomly selected and non-fasting rabbits by the intravenous injection over $10 \mathrm{~min}$ of $150 \mathrm{mg} \mathrm{kg}$-1 body weight of alloxan monohydrate (Sigma) in freshly prepared $5 \%$ aqueous solution. During the subsequent 24 hrs, regular Dextrostix (Ames) blood glucose measurements were made, and 5-10 ml aliquots of intravenous $50 \%$ dextrose were administered to hypoglycaemic rabbits to prevent convulsions. Supplementary feeding of bran and fresh vegetables was provided for control and diabetic animals during the first post-induction week. At four days post-induction, diabetic animals were given a single subcutaneous injection of 4 IU protamine zinc insulin. The animals were maintained for two months and weekly weighing and blood glucose measurements (Beckmann glucose oxidase $\mathrm{O}_{2}$ uptake method) performed in the diabetic rabbits. Nine per cent of the rabbits failed to become sufficiently diabetic and were excluded from the study.

Electrophysiological recordings The rats were anaesthetized with ether and laid on their right side on an electrically heated pad in a warm room. The exposed hind quarters and left leg were covered with a jacket made from a parallel array of silicone rubber tubes through which was circulated water maintained at $37^{\circ} \mathrm{C}$. Recordings were made only when the rectal temperature and skin temperature over the thigh and ankle were all at $37 \pm 0.5^{\circ} \mathrm{C}$. The electrically-heated pad was employed to warm the animals if they were below this temperature at the start of the experiment.

The rabbits were anaesthetized with an intravenous injection of pentobarbitone sodium (Sagatal $60 \mathrm{mg}$ per $\mathrm{ml}$, May and Baker) at a dosage of $0.3 \mathrm{ml} \mathrm{kg}^{-1}$ body weight with supplementary ether and placed on an electrically heated pad in a warm room. The pelvis and right hind limb were fixed with strapping with the latter held in full extension. The rectal and calf intramuscular temperature was recorded with thermistor probes during the experiment and recordings were only made when these were both at $39 \pm 0.5^{\circ} \mathrm{C}$. For both species, motor nerve conduction velocity was measured by the method described previously. ${ }^{9}$ A concentric needle electrode (Disa type K0511) was inserted into the muscles of the first interosseous space of the foot. The sciatic nerve was stimulated through a needle electrode at the sciatic notch and the tibial nerve posterior to the medial malleolus with just supramaximal $0.1 \mathrm{~ms}$ duration stimuli delivered from a Devices isolated stimulator at a rate of 1 per second. The evoked muscle action potentials were suitably amplified and displayed on a Medelec fibre optic recording oscilloscope. A storage oscilloscope helped to ensure that the earliest deflection was obtained and that the responses were comparable for stimulation at both sites. Conduction time was measured from photographic paper records. The distance between the two stimulating electrodes was measured with a ruler.

\section{Results}

\section{Observations on rats}

Measurements of tibial motor nerve conduction velocity were obtained in 10 rats before and eight weeks after the induction of diabetes with streptozotocin. Over this period the weight of the animals fell from a mean of $556 \mathrm{~g}$ to $372 \mathrm{~g}$. The blood glucose concentration at the time of the latter recording ranged from $21 \cdot 3-33.0 \mathrm{mmol} \mathrm{l}^{-1}$ (383$594 \mathrm{mg} \mathrm{dl}^{-1}$ ) with a mean value of $24.8 \mathrm{mmol} \mathrm{1}^{-1}$ (446 $\left.\mathrm{mg} \mathrm{dl}^{-1}\right)$. The values obtained for conduction velocity are shown in fig 1 . The mean value before the induction of diabetes was $52 \cdot 8 \pm 2 \cdot 3 \mathrm{~m} \mathrm{~s}^{-1}$. Eight weeks after the induction of diabetes it was $51 \cdot 3 \pm 3.6 \mathrm{~m} \mathrm{~s}^{-1}$. This difference is not statistically significant ( $p>0.05$, matched-pair $t$ test).

In 10 further animals, in addition to the induction of diabetes, the animals were given a dietary supplement of myoinositol ( $1 \%$ by weight). Measurements of tibial motor nerve conduction velocity were again obtained before the induction of diabetes and eight weeks later (fig 1). Over this period, the mean weight of the animals fell 


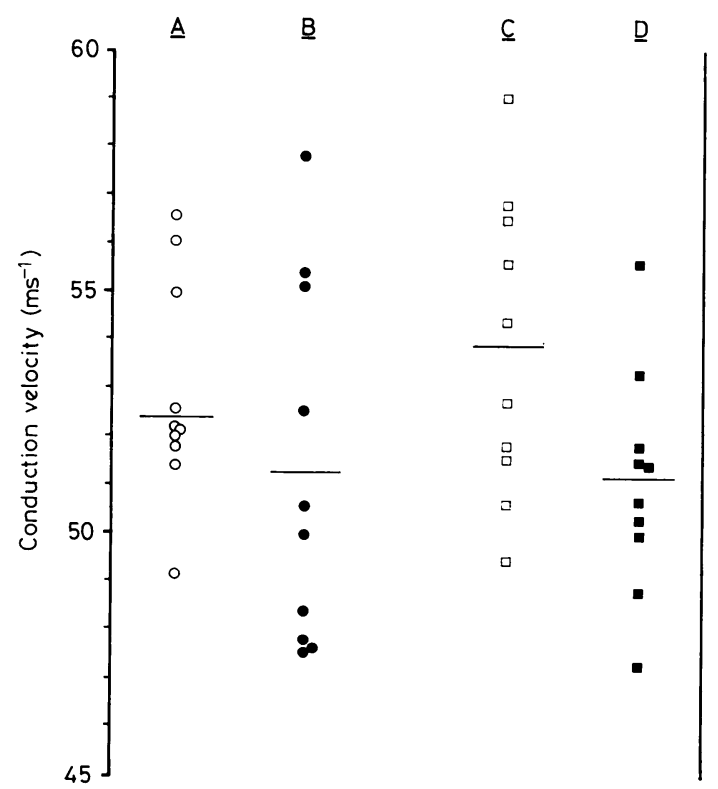

Fig 1 Tibial motor nerve conduction velocity in the rat. The values in columns $A$ and $C$ are for two groups of 10 animals before the induction of diabetes with streptozotocin and in $B$ and $D, 8$ weeks after the induction of diabetes. In $D, 1 \%$ dietary myoinositol supplementation was administered. The mean values are indicated by the horizontal lines.

from $562 \mathrm{~g}$ to $397 \mathrm{~g}$. The blood glucose concentration at the time of the latter recording ranged from 19.4-31.2 $\mathrm{mmol} \mathrm{l}^{-1}\left(350-562 \mathrm{mg} \mathrm{dl}^{-1}\right)$ with a mean of $23.7 \mathrm{mmol} \mathrm{l}^{-1}\left(427 \mathrm{mg} \mathrm{dl}^{-1}\right)$. The mean value for conduction velocity before the induction of diabetes was $53 \cdot 8 \pm 3 \cdot 1 \mathrm{~m} \mathrm{~s}^{-1}$ and after the eight week diabetic period, $51 \cdot 0 \pm 2 \cdot 3 \mathrm{~m} \mathrm{~s}^{-1}$. Thus the mean conduction velocities after diabetes for animals with and without dietary myoinositol supplements were $51 \cdot 0 \pm 2 \cdot 3$ and $51 \cdot 3 \pm 3.6 \mathrm{~m} \mathrm{~s}^{-1}$ respectively. A two way, repeated measures analysis of variance was performed on these data (see table). It showed that the small reduction in conduction velocity for all the rats following diabetes (from $53.3 \pm 2.7$ to $51 \cdot 1 \pm 3.0 \mathrm{~m} \mathrm{~s}^{-1}$ ) was statistically significant, but that the inositol supplement had no detectable effect whatsoever. Even although a statistically significant effect was recorded for diabetes it was very small indeed. Too much should not be read into such a difference between measurements separated by two months.

Observations on rabbits

Motor nerve conduction velocity was measured in 14 alloxan-diabetic rabbits eight weeks after

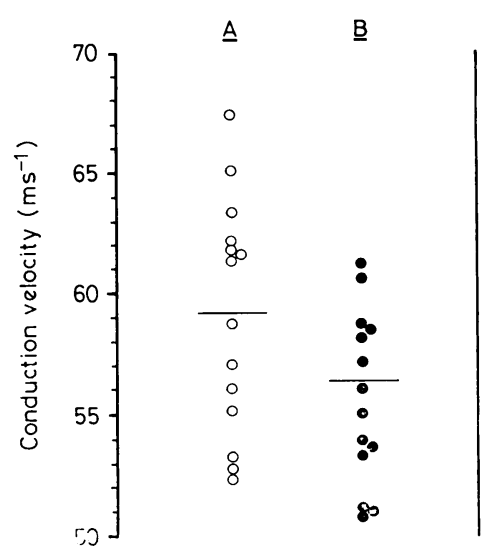

Fig 2 Tibial motor nerve conduction velocity in the rabbit in a control group $(A)$ and 8 weeks after the induction of diabetes with alloxan $(B)$. The mean values are indicated by the horizontal lines.

Table Analysis of variance results

\begin{tabular}{|c|c|c|c|c|}
\hline Source of variation & $\begin{array}{l}\text { Sum of } \\
\text { squares }\end{array}$ & $\begin{array}{l}\text { Degrees of } \\
\text { freedom }\end{array}$ & $\begin{array}{l}\text { Mean } \\
\text { squares }\end{array}$ & F ratio \\
\hline $\begin{array}{l}\text { Between rats } \\
\text { Diet } \\
\text { rats within groups }\end{array}$ & $\begin{array}{r}182 \cdot 909 \\
1.024 \\
181 \cdot 885\end{array}$ & $\begin{array}{r}19 \\
1 \\
18\end{array}$ & $\begin{array}{r}-1 \cdot 02 \\
10 \cdot 10\end{array}$ & $\begin{array}{l}- \\
0 \cdot 10\end{array}$ \\
\hline $\begin{array}{l}\text { Within rats } \\
\text { Diabetes } \\
\text { Interaction, diet } \\
\text { with diabetes } \\
\text { Diabetes X rats } \\
\text { within groups }\end{array}$ & $\begin{array}{r}181 \cdot 95 \\
47 \cdot 961 \\
3 \cdot 844 \\
103 \cdot 145\end{array}$ & $\begin{array}{r}20 \\
1 \\
1\end{array}$ & $\begin{array}{r}- \\
47 \cdot 96 \\
3 \cdot 84 \\
7 \cdot 23\end{array}$ & $\begin{array}{l}- \\
6.63 \\
0.53 \\
-\end{array}$ \\
\hline
\end{tabular}

0.05 significance level for $F(1,18)=4 \cdot 41$

the induction of diabetes and in 14 age-matched control animals. The blood glucose concentration in the diabetic rabbits during the eight week survival period was consistently between 20 and $40 \mathrm{mmol} \mathrm{l}^{-1}\left(360-720 \mathrm{dl}^{-1}\right)$. Diabetic animals failed to gain weight normally and at the time of the second recording weighed on average $0.55 \mathrm{~kg}$ less than the control group. Twenty per cent developed clinically observable cataracts, usually about the fourth week after the induction of diabetes. The results for tibial motor nerve conduction velocity are shown in fig 2 . The mean value for the diabetic rabbits was $55.5 \pm 3.6 \mathrm{~m} \mathrm{~s}^{-1}$ and in the control group, $59 \cdot 0 \pm 4 \cdot 8 \mathrm{~m} \mathrm{~s}^{-1}$. Student's $t$ test shows that this difference is significant at the 0.05 level.

\section{Discussion}

The present results show no significant reduction in motor nerve conduction velocity for the two 
groups of diabetic rats, that is, with and without dietary myoinositol supplements, when analysed separately. When the two are combined, there is a very small but statistically significant reduction amounting to $2 \cdot 2 \mathrm{~m} \mathrm{~s}^{-1}$. The rats employed in this study were of sufficient age ( 9 months) for it to be certain that nerve fibre diameter, and therefore presumably conduction velocity, were no longer increasing. The rabbits used were not fully mature, but had passed the period of most rapid increase in nerve conduction velocity (C Fowler, R W Gilliatt and C Krarup, personal communication). A maturational retardation as the explanation for the difference between the diabetic and control animals cannot therefore be entirely excluded. Previous studies on rats have mostly compared diabetic animals with age-matched controls and have used immature animals. The present results therefore strongly suggest that the "reduction" in conduction velocity that has been found is mainly a difference related to retarded maturation in the diabetic animals. In the recent study by Sugimura et $a l^{23}$ conduction velocity in streptozotocin-diabetic rats $\left(51.9 \mathrm{~m} \mathrm{~s}^{-1}\right)$ was intermediate between those of onset-control $\left(41.1 \mathrm{~m} \mathrm{~s}^{-1}\right)$ and end-control $\left(56.0 \mathrm{~m} \mathrm{~s}^{-1}\right)$ animals. The duration of diabetes was not given. These values suggest that immature animals were used and support the view that a maturational deficit in the diabetic animals at least partly explains the findings.

The small size of the reduction in conduction velocity found in the rats in the present study makes it difficult to be certain whether it is directly related to the diabetes or to unknown and uncontrolled factors in the experiment. However, taking the rat and rabbit results together, it is clear that diabetes of this severity and duration can only be responsible for a very small diminution in conduction velocity, substantially less than the reductions reported in previous studies. These have amounted to as much at $20-25 \%$. $^{17910}$ Jefferys and Brismar ${ }^{24}$ were unable to demonstrate any reduction in conduction velocity from observations on excised nerve from streptozotocindiabetic rats and found normal electrical properties for the nodes of Ranvier.

Relating these observations to the previous reports on nerve fibre size in streptozotocindiabetic rats, it is evident that the "reduction" in diameter reported by Jakobsen and Lundbaek ${ }^{12}$ and Jakobsen ${ }^{11}{ }^{17}$ refers to a difference between diabetic and control animals. Sharma et $a l^{18}$ found, in serial observations before and five weeks after the induction of diabetes, that fibre size in the tibial nerve did not diminish. The values for maximal fibre diameter were 11.94 and $12.10 \mu \mathrm{m}$ respectively; these did not differ significantly. The corresponding values for a control group were 10.79 and $11.66 \mu \mathrm{m}$ respectively; this increase was statistically significant. These observations therefore again imply a maturational deficit in diabetic nerve. Similar findings have since been obtained with a survival period of 10 weeks (Sharma, Bajada and Thomas, unpublished observations).

Despite these considerations, it is possible that some degree of axonal shrinkage occurs in diabetic animals since Sugimura et $a l^{23}$ have reported that although axon circumference and the number of myelin lamellae are unchanged by the induction of diabetes, axonal area is less. The circularity of the axons from the diabetic animals is also reduced. It was therefore suggested that axonal shrinkage might occur as the result of an elevated extracellular osmolarity, as similar changes are observed following treatment with hyperosmolar fixatives. This important observation requires further study. It is of interest that Mendell et $a l^{25}$ found reduced conduction velocity in the spontaneously diabetic (BB) Wistar rat without conspicuous associated morphological changes. It is possible that more extensive changes may develop in experimental diabetes after longer periods. Powell $e t a l^{26}$ reported the occurrence of demyelination and nerve fibre loss, together with the presence of intraaxonal glycogenosomes, in the sciatic nerves of rats after two years of alloxan-induced diabetes. The interpretation of this finding is handicapped by the observation that similar changes occur with aging in normal rats, ${ }^{2} 728$ although Powell et $a l^{29}$ later found that glycogenosomes were significantly more common in diabetic animals. It is also possible that the genetically determined diabetes in the $d b / d b$ mouse or in the Chinese hamster may provide useful models to study the longer term effects of diabetes in animals. Histological changes have been reported in the $d b / d b$ mouse ${ }^{3031}$ and in the Chinese hamster. ${ }^{32}$ Reduced nerve conduction velocity concomitant with the onset of diabetes was also reported by Sima and Robertson. ${ }^{30}$ So far, these observations have been made on relatively small numbers of animals and require confirmation in more extensive studies. The importance of changes in myoinositol concentration in peripheral nerve in diabetes has yet to be established. ${ }^{33}$ It is a precursor of the polyphosphoinositides which are present in membranes, including those of neurons. It has been postulated that the polyphosphoinositides may be involved in the regulation of ionic transfer across the 
axolemma. ${ }^{34-36}$ The myoinositol concentration of peripheral nerve is known to be reduced in alloxan-induced and streptozotocin-induced diabetes in rats. ${ }^{10} 37$ As already mentioned, Greene et $a l^{10}$ found that the addition of $1 \%$ dietary myoinositol supplements prevented the reduction in nerve conduction velocity that they found in streptozotocin-diabetic rats. This was not confirmed by Jefferys et al. ${ }^{22}$ In the present results, conduction velocity did not differ between the diabetic rats with and without myoinositol supplements: the values for these two groups differed by only $0.3 \mathrm{~m} \mathrm{~s}^{-1}$. The administration of dietary myoinositol has been claimed to improve nerve conduction in cases of diabetic neuropathy in man, ${ }^{38}{ }^{39}$ but no clinical benefit has been noted in neuropathic symptoms. ${ }^{40}$

In conclusion, the present study establishes that when careful steps are taken to control temperature and to avoid the complications introduced by maturational changes, the reduction in nerve conduction velocity produced by experimental diabetes in rats and rabbits is found to be small. No influence from low dosage dietary myoinositol supplements is detectable.

Financial support from the Medical Research Council, the British Diabetic Association and the National Fund for Research into Crippling Diseases is gratefully acknowledged. Dr Bajada was in receipt of an Australian Neurological Foundation Travel Grant during part of this work. The streptozotocin was kindly supplied by the Drug Development Branch, Division of Cancer Treatment, National Cancer Institute, National Institutes of Health, Bethesda, Md, USA, and the blood glucose estimations were performed by the Department of Chemical Pathology, Royal Free Hospital School of Medicine. The assistance of the Comparative Biology Unit, Royal Free Hospital School of Medicine, is also gratefully acknowledged.

\section{References}

1 Eliasson SG. Nerve conduction changes in experimental diabetes. J Clin Invest 1964; 43:2353-8.

2 Eliasson SG. Properties of isolated nerve fibres from alloxanized rats. J Neurol Neurosurg Psychiatry 1969; 32:525-9.

3 Preston GM. Peripheral neuropathy in the alloxandiabetic rat. J Phy'siol (Lond) 1967; 189:49P.

4 Lovelace RE. Experimental neuropathy in rats made diabetic with alloxan. EEG Clin Neurophysiol 1968; 25:393.

5 Hildebrand J, Joffroy J, Graff G, Coërs C. Neuro- muscular changes with alloxan hyperglycemia. Electrophysiological, biochemical and histological study in rats. Arch Neurol (Chic) 1968; 18:633-41.

6 Gabbay KH. Role of sorbitol pathway in neuropathy In: Camerini-Dávalos RA and Cole HS ed. Vascular and Neurological Changes in Early Diabetes. New York: Academic Press, 1973.

7 Miyoshi T, Goto I. Serial in vivo determinations of nerve conduction velocity in rat tails. Physiological and pathological changes. Electroencephalogr Clin Neurophysiol 1973; 35:125-31.

8 Goto I, Peters HA. Serial in vivo determination of motor conduction velocity in tails of alloxanized non-diabetic and diabetic rats. $J$ Neurol Sci 1974; 22:177-82.

9 Sharma AK, Thomas PK. Peripheral nerve structure and function in experimental diabetes. $J$ Neurol Sci 1974; 23:1-15.

10 Greene DA, DeJesus PV, Winegrad AI. Effects of insulin and dietary myoinositol on impaired peripheral motor nerve conduction velocity in acute streptozotocin diabetes. J Clin Invest 1975; 55:1326-36.

11 Jakobsen J. Early and preventable changes of peripheral nerve structure and function in insulindeficient diabetic rats. J Neurol Neurosurg Psychiatry 1979; 42:509-18.

12 Jakobsen J, Lundbaek K. Neuropathy in experimental diabetes. An animal model. Brit Med J 1976; 2:278-9.

13 Gregersen G. Diabetic neuropathy: influence of age, sex, metabolic control, and duration of diabetes on motor conduction velocity. Neurology (Minneap) 1967; 17:972-80.

14 Ward JD, Barnes CG, Fisher DJ, Jessop JD, Baker RWR. Improvement in nerve conduction following treatment in newly-diagnosed diabetics. Lancet $1971 ; 1: 428-31$.

15 Mayher WE, Mimbs JW, Allen MB. Hypophysectomy in experimental diabetic neuropathy. Surg Forum 1967; 18:447-9.

16 Jakobsen J. Axonal dwindling in early experimental diabetes. II. A study of isolated nerve fibres. Diabetologia 1976; 12:547-53.

17 Jakobsen J. Axonal dwindling in early experimental diabetes. I. A study of cross-sectioned nerves. Diabetologia 1976; 12:539-46.

18 Sharma AK, Thomas PK, De Molina AF. Peripheral nerve fiber size in experimental diabetes. Diabetes 1977; 26:689-92.

19 Birren JE, Wall PD. Age changes in conduction velocity, refractory period, number of fibers, connective tissue space and blood vessels in sciatic nerve of rats. J Comp Neurol 1956; 104:1-16.

20 Sharma AK, Bajada S, Thomas PK. Age changes in the tibial and plantar nerves of the rat. $J$ Anat 1980; 130:417-28.

21 Sharma AK, Bajada S, Thomas PK. Effect of streptozotocin diabetes on growth in nerve fibre diameter and on skeletal growth in rats. Acta Neuropathol (Berl), in press. 
22 Jefferys JGR, Palmano KP, Sharma AK, Thomas PK. Influence of dietary myoinositol on nerve conduction and phospholipids in normal and diabetic rats. J Neurol Neurosurg Psychiatry 1978; 41:333-9.

23 Sigimura K, Windebank A, Natarajan V, Lambert $\mathrm{E}$, Schmid H, Dyck PJ. Interstitial hyperosmolarity may cause axis cylinder shrinkage in streptozotocin-diabetic nerves. Neurology (Minneap) 1980; 30:434.

24 Jefferys JGR, Brismar T. Analysis of peripheral nerve function in streptozotocin diabetic rats. J Neurol Sci 1980; 48:435-44.

25 Mendell JR, Sahenk Z, Warmolts JR, Marshall JK. Peripheral nerve abnormalities in the spontaneously diabetic ("BB") Wistar rat. Neurology (Minneap) 1980; 30:434.

26 Powell H, Knox D, Lee S, Charters AC, Orloff M, Garrett R, Lampert P. Alloxan diabetic neuropathy: electron microscopic studies. Neurology (Minneap) 1977; 27:60-66.

27 Grover-Johnson N, Spencer PS. Peripheral nerve abnormalities in aging rats (abstract). J Neuropath Exp Neurol 1979; 38:316.

28 Thomas PK, King RHM, Sharma AK. Age changes in the peripheral nerves of rats: an ultrastructural study. Acta Neuropath (Berl) $1980 ; 52: 1-6$.

29 Powell HC, Ward HW, Garrett RS, Orloff MJ, and Lampert PW. Glycogen accumulation in the nerves and kidney of chronically diabetic rats. A quantitative electron microscope study. J Neuropath Exp Neurol 1979; 38:114-27.

30 Sima AAF, Robertson DM. Peripheral neuropathy in the mutant diabetic mouse C57BL/Ks (db/db). Acta Neuropath (Berl) 1978; 41:85-9.
31 Sima AAF, Robertson DM. Peripheral neuropathy in the diabetic mutant mouse. An ultrastructural study. Lab Invest 1979; 40:627-32.

32 Schlaepfer WW. Gerritson GC, Dulin WE. Segmental demyelination in the distal peripheral nerves of chronically diabetic Chinese hamsters. Diabetologia 1974; 10:541-8.

33 Clements RS. Diabetic neuropathy-new concepts of its etiology. Diabetes 1979; 28:604-11.

34 Kai M, Hawthorne JN. Physiological significance of polyphosphoinositides in brain. Ann NY Acad Sci 1969; 165:761-73.

35 Hawthorne JN, Kai M. Metabolism of phosphoinositides. In: Lajtha J ed Handbook of Neurochemistry. New York: Plenum Press, 1970; 491508.

36 Hendrickson HS, Reinertsen JL. Phosphoinositide interconversion: a model for control of $\mathrm{Na}+$ and $\mathrm{K}^{+}$permeability in the nerve axon membrane. Biochem Biophys Res Comm 1971; 44:1258-64.

37 Stewart A, Sherman WR Kurien MM, Moonsammy GI, Wisgerhof M. Polyol accumulation in nervous tissue of rats with experimental diabetes and galactosemia. $J$ Neurochem 1967; 14:1057-66.

38 Clements RS Jr, Vourganti B, Kuba T, Oh SJ, Darnell B. Myoinositol intake and peripheral nerve function in diabetic neuropathy. Metabolism 1978; 28:477-82.

39 Salway JG, Whitehead L, Finnegan JA, Karunanayaka A, Barnett D, Payne RB. Effect of myoinositol on peripheral nerve function in diabetes. Lancet 1978; 2:1282-4.

40 Gregersen G, Børsting H, Theil P, Servo C. Myoinositol and function of peripheral nerves in human diabetics. Acta Neurol Scand 1978; 58: 241-8. 